\title{
A Link between Impaired Lung Function and Increased Cardiac Stress
}

\author{
Siegfried Wieshammer ${ }^{a}$ Jens Dreyhaupt ${ }^{c}$ Beate Basler ${ }^{b}$ \\ a Medizinische Klinik I and b Medizinische Klinik II, Klinikum Offenburg, Offenburg, and 'Institut für Biometrie, \\ Universität UIm, Ulm, Germany
}

For editorial comment see p. 353

\section{Key Words}

C-reactive protein $\cdot$ Natriuretic peptides $\cdot$ Systemic inflammation $\cdot$ Heart disease $\cdot$ Lung disease $\cdot$ Chronic obstructive pulmonary disease $\cdot$ Cardiac stress

\begin{abstract}
Background: Patients with impaired lung function often have systemic inflammation. C-reactive protein (CRP) and Nterminal pro-brain natriuretic peptide (NT-proBNP) are markers for inflammation and cardiac stress, respectively. Objectives: To evaluate the association between both markers and the potential impacts of lung disease on this relationship. Methods: CRP and NT-proBNP were prospectively measured in 697 consecutive outpatients $(57.5 \pm 16.4$ years) with chronic dyspnea. The patients were stratified into quartiles according to CRP levels (quartile 1: median CRP $0.35 \mathrm{mg} / \mathrm{l}$; quartile 2: $1.50 \mathrm{mg} / \mathrm{l}$; quartile 3: $3.62 \mathrm{mg} / \mathrm{l}$; quartile 4: 10.90 $\mathrm{mg} / \mathrm{l})$ and classified into 2 categories based on the presence $(n=176)$ or absence $(n=521)$ of heart disease. Results: Patients with at least moderately severe airway obstruction and those with interstitial lung disease had higher CRP values than patients without lung disease (median 3.50 vs. 4.34 vs. $1.80 \mathrm{mg} / \mathrm{l}$, respectively; $p<0.01$ ). In patients without heart disease, NT-proBNP values increased from CRP quartiles 1-3 to quartile 4 (median 47.4 vs. $82.1 \mathrm{pg} / \mathrm{ml} ; \mathrm{p}<0.01$ ) after ad-
\end{abstract}

justing for important covariates such as age, sex, body mass index, renal function and arterial hypertension. Likewise, the values for NT-proBNP were lower in CRP quartiles 1-3 than in quartile 4 (median 212.0 vs. $647.7 \mathrm{pg} / \mathrm{ml} ; \mathrm{p}<0.01$ ) in patients with heart disease after additional adjustment for the type of cardiac disorder. Lung disease had no direct effect on the relationship between CRP and NT-proBNP. Conclusion: Systemic inflammation that originates in the lung places an excess burden on the heart, which may contribute to the functional impairment of patients with advanced pulmonary disease.

Copyright $\odot 2009$ S. Karger AG, Basel

\section{Introduction}

A state of low-grade systemic inflammation exists in a number of chronic diseases such as heart failure [1], renal failure [2] and obstructive and restrictive pulmonary disease $[3,4]$. Inflammation that originates in the lung and extends beyond the pulmonary system is thought to contribute to the cardiovascular consequences of lung disease [5]. The severity of the inflammatory process can be assessed by measuring C-reactive protein (CRP). Furthermore, an inverse relation was found between CRP and exercise capacity in patients with chronic obstructive

\section{KARGER}

Fax +4161306 1234

E-Mail karger@karger.ch

www.karger.com
(C) 2009 S. Karger AG, Basel

0025-7931/10/0795-0355\$26.00/0

Accessible online at:

www.karger.com/res
Dr. S. Wieshammer

Medizinische Klinik I, Klinikum Offenburg

Ebertplatz 12, DE-77654 Offenburg (Germany)

Tel. +49781 472 2401, Fax +49 7814722402

E-Mail siegfried.wieshammer@og.ortenau-klinikum.de 
pulmonary disease (COPD) after adjustment for age, sex, free fat mass index and the forced expiratory volume in $1 \mathrm{~s}\left(\mathrm{FEV}_{1}\right)$ [6]. There is abundant evidence of abnormal cardiovascular responses to exercise in COPD [7]. N-terminal pro-brain natriuretic peptide (NT-proBNP) has gained wide acceptance as a quantitative indicator of cardiac stress and exercise cardiac reserve [8-10]. Our study aimed to determine the relationship between CRP and NT-proBNP in patients with chronic dyspnea. A reduced $\mathrm{FEV}_{1}$ is an indicator of mortality risk and may account for $24-26 \%$ of all deaths related to ischemic heart disease [11]. Both CRP and NT-proBNP provide prognostic information [12-14]. Therefore, another objective of this study was to examine whether coexisting lung disease affects the response of NT-proBNP to CRP.

\section{Patients and Methods}

\section{Patients}

This prospective monocenter study included consecutive outpatients referred to the pulmonology service of an academic teaching hospital from January 2005 to January 2007 for evaluation of dyspnea for a duration of at least 2 weeks, as previously described [15]. Dialysis-dependent renal failure and information about previously measured NT-proBNP levels were utilized as exclusion criteria. Patients were not excluded if they had ongoing deterioration of their pulmonary or cardiac disease, or concomitant chronic inflammatory disorders such as impaired renal function, and rheumatoid or endocrine disorders. The study was approved by the ethics committee of the Baden-Württemberg State Chamber of Physicians.

\section{Diagnostic Procedures}

Patients underwent a diagnostic work-up for heart and lung disease, including chest X-ray, pulmonary function tests, resting electrocardiogram, exercise treadmill electrocardiogram according to the Bruce protocol, and Doppler echocardiography. Existing lung disease was categorized as asthma or COPD according to accepted guidelines $[16,17]$, or as other lung diseases such as interstitial lung disease, pneumoconiosis, chronic fibrotic tuberculosis, or rare disorders (table 1). An obstructive ventilatory defect was diagnosed using the lower limit of normal for the $\mathrm{FEV}_{1} /$ vital capacity ratio and lung volumes $[18,19]$. The degree of airway obstruction was stratified into the following 3 levels of severity based on the $\mathrm{FEV}_{1}$ : mild to moderate $\left(\mathrm{FEV}_{1} \geq 60 \%\right.$ of predicted), moderately severe $\left(\mathrm{FEV}_{1} 50-59 \%\right.$ of predicted) or severe to very severe $\left(\mathrm{FEV}_{1}<50 \%\right.$ of predicted) [18]. The COPD patients were also categorized according to the Global Initiative for Chronic Obstructive Lung Disease stages. The patients were further classified into 2 groups based on the presence or absence of heart disease. Heart disease was diagnosed as the presence of at least 1 of the following findings and was categorized into 6 cardiac characteristic groups as follows: (1) left ventricular hypertrophy (enddiastolic septal wall thickness $\geq 12 \mathrm{~mm}$ or positive Sokolow index in the presence of arterial hypertension); (2) exercise-induced myocardial ischemia due to angiographically proven coronary disease; (3) at least mild aortic stenosis (mean transvalvular pressure gradient $\geq 20 \mathrm{~mm} \mathrm{Hg}$ ), at least moderate aortic regurgitation, at least moderate mitral regurgitation, severe tricuspid regurgitation, and atrial septal defects or pericardial effusion; (4) pulmonary hypertension (peak systolic gradient across the tricuspid valve measured with continuous wave Doppler $\geq 35 \mathrm{~mm}$ $\mathrm{Hg}$ ); (5) atrial fibrillation or left bundle branch block, and (6) impaired left ventricular systolic function. All of these cardiac characteristic groups were associated with an elevated NT-proBNP level in the above-mentioned ranking order, as previously shown [15]. The presence of arterial hypertension or minor echocardiographic findings was also recorded. The latter category included mild aortic regurgitation, mild mitral regurgitation and a borderline systolic pressure gradient of 30-34 mm Hg across the tricuspid valve. Blood samples were assayed for NT-proBNP using an automated ELISA assay (Roche Diagnostics, Mannheim, Germany), which was supplied free of charge by the manufacturer. CRP was measured using a highly sensitive assay (Cobas Integra, CRPLX; Roche Diagnostics). The lower limit of detection was 0.71 $\mathrm{mg} / \mathrm{l}$. A value of $0.35 \mathrm{mg} / \mathrm{l}$ was assigned to the 92 patients with undetectable CRP levels. The estimated glomerular filtration rate (eGFR) was calculated [20]. No commercial entity was involved in the design of the study, the statistical analysis or the preparation of the manuscript.

\section{Data Analysis}

The CRP, NT-proBNP and eGFR values displayed skewed distributions and are presented as medians. Multiple regression analysis was used to evaluate the effects of heart disease [1], age [21], sex [22], body mass index (BMI) [23], eGFR [24] as well as the presence of asthma, COPD [12] and other lung disease [4] on CRP. The regression models were additionally adjusted for the severity of airway obstruction in a second step to find out whether the presence of COPD remained predictive of CRP levels after adjustment for the severity of airway obstruction. Analysis of variance for log-transformed values and the 2-sample $t$ test for log-transformed values were used to compare CRP values among patient groups. The NT-proBNP values were transformed to their natural logarithm to achieve normality. The CRP values were divided into quartiles. Dummy variables were used to code CRP quartile membership. Using the highest quartile as a reference group, the effect of CRP quartile membership on NT-proBNP was analyzed by a multiple linear regression model. The covariates considered were age, BMI and eGFR as continuous variables, and sex, the presence of arterial hypertension, minor echocardiographic findings, asthma, COPD, other lung disease and the severity of airway obstruction as categorical variables. A possible interaction of age and sex was accounted for by adding an interaction term to the regression models. In the group of patients with heart disease, the models were additionally adjusted for the cardiac characteristic groups. To compare the effect of CRP quartile 4 membership on NT-proBNP values with the effects of other important covariates, the standardized regression coefficients were calculated.

Given the exploratory nature of the study, the test results should not be interpreted as confirmatory, and no adjustment for multiple testing was performed. A p value $<0.05$ was considered significant. Analyses were performed using SAS, version 9.1 (SAS Institute, Chicago, Ill., USA). 
Table 1. Patient characteristics, distribution of heart and lung disease, and values for NT-proBNP according to quartiles of CRP levels

\begin{tabular}{|c|c|c|c|c|c|c|}
\hline & \multirow{2}{*}{$\begin{array}{l}\text { All patients } \\
\text { CRP } \\
\text { (median } 2.40 \mathrm{mg} / \mathrm{l} \\
\mathrm{n}=697 \text { ) }\end{array}$} & \multicolumn{5}{|l|}{ CRP quartiles } \\
\hline & & $\begin{array}{l}\text { quartile } 1 \\
\text { CRP }<1.01 \mathrm{mg} / \mathrm{l} \\
(\text { median } 0.35 \mathrm{mg} / \mathrm{l} \\
\mathrm{n}=175)\end{array}$ & $\begin{array}{l}\text { quartile } 2 \\
\text { CRP } 1.01-2.40 \mathrm{mg} / \mathrm{l} \\
\text { (median } 1.50 \mathrm{mg} / \mathrm{l} \\
\mathrm{n}=175 \text { ) }\end{array}$ & $\begin{array}{l}\text { quartile } 3 \\
\text { CRP } 2.41-5.80 \mathrm{mg} / \mathrm{l} \\
\text { (median } 3.62 \mathrm{mg} / \mathrm{l} \\
\mathrm{n}=174 \text { ) }\end{array}$ & $\begin{array}{l}\text { quartile } 4 \\
\text { CRP }>5.80 \mathrm{mg} / \mathrm{l} \\
(\text { median } 10.90 \mathrm{mg} / \mathrm{l} \\
\mathrm{n}=173 \text { ) }\end{array}$ & $\begin{array}{l}\text { comparison } \\
\text { of CRP } \\
\text { quartiles, } p\end{array}$ \\
\hline Age $^{a}$, years & $57.5 \pm 16.4$ & $51.3 \pm 17.8$ & $58.0 \pm 15.6$ & $58.7 \pm 15.3$ & $62.1 \pm 15.1$ & $<0.01^{\mathrm{c}}$ \\
\hline Age $>65$ years, $\%$ & 39.6 & 27.4 & 40.6 & 39.1 & 51.5 & $<0.01^{\mathrm{d}}$ \\
\hline $\mathrm{BMI}^{\mathrm{a}}$ & $27.6 \pm 5.2$ & $25.2 \pm 3.8$ & $27.6 \pm 4.2$ & $28.4 \pm 5.1$ & $29.3 \pm 6.5$ & $<0.01^{\mathrm{c}}$ \\
\hline Female, \% & 47.6 & 46.9 & 44.6 & 50.6 & 48.6 & $0.51^{\mathrm{d}}$ \\
\hline Arterial hypertension, \% & 43.6 & 27.4 & 44.6 & 49.4 & 53.2 & $<0.01^{\mathrm{d}}$ \\
\hline Diabetes, \% & 8.8 & 6.3 & 8.0 & 8.6 & 12.1 & $0.06^{\mathrm{d}}$ \\
\hline $\mathrm{eGFR}^{\mathrm{b}}, \mathrm{ml} / \mathrm{min} / 1.73 \mathrm{~m}^{2}$ & $85.8[71.5-101.3]$ & 88.5 [74.2-109.9] & $89.6[74.7-101.3]$ & $84.5[70.3-100.5]$ & $81.0[65.6-95.7]$ & $<0.01^{\mathrm{f}}$ \\
\hline Heart disease, \% & 25.3 & 15.4 & 25.1 & 23.0 & 37.6 & $<0.01^{\mathrm{d}}$ \\
\hline $\begin{array}{l}\text { Impaired left ventricular function } \\
\text { Atrial fibrillation and/or left bundle }\end{array}$ & $30 / 697(4.3)$ & $3 / 175(1.7)$ & $7 / 175(4.0)$ & $7 / 174(4.0)$ & $13 / 173(7.5)$ & $0.30^{\mathrm{d}}$ \\
\hline branch block ${ }^{g}$ & $50 / 697(7.2)$ & $9 / 175(5.1)$ & $14 / 175(8.0)$ & $6 / 174(3.4)$ & $21 / 173(12.1)$ & $0.80^{\mathrm{d}}$ \\
\hline Pulmonary hypertension & $61 / 697(8.7)$ & $6 / 175(3.4)$ & $12 / 175(6.9)$ & $13 / 174(7.5)$ & $30 / 173(17.3)$ & $0.01^{\mathrm{d}}$ \\
\hline Valvular or pericardial disease or ASD & $26 / 697(3.7)$ & $2 / 175(1.1)$ & $4 / 175(2.3)$ & $8 / 174(4.6)$ & $12 / 173(6.9)$ & $0.08^{\mathrm{d}}$ \\
\hline Exercise-induced myocardial ischemia & $12 / 697(1.7)$ & $4 / 175(2.3)$ & $1 / 175(0.6)$ & $2 / 174(1.1)$ & $5 / 173(2.9)$ & $0.63^{\mathrm{d}}$ \\
\hline Left ventricular hypertrophy & $66 / 697(9.5)$ & $10 / 175(5.7)$ & $19 / 175(10.9)$ & $19 / 174(10.9)$ & $18 / 173(10.4)$ & $0.22^{\mathrm{d}}$ \\
\hline Lung disease, $\%$ & 78.6 & 71.4 & 80.6 & 77.6 & 85.0 & $<0.01^{\mathrm{d}}$ \\
\hline$\geq$ moderately severe airway obstruction & $129 / 697(18.5)$ & $19 / 175(10.9)$ & $28 / 175(16.0)$ & $29 / 173(16.8)$ & $53 / 173(30.6)$ & $<0.01^{\mathrm{d}}$ \\
\hline Hypercapnic respiratory failure & $20 / 697(2.9)$ & $1 / 175(0.6)$ & $3 / 175(1.7)$ & $3 / 174(1.7)$ & $13 / 173(7.5)$ & $<0.01^{\mathrm{d}}$ \\
\hline COPD & $124 / 697(17.8)$ & 20/175 (11.4) & $29 / 175(16.6)$ & 29/174 (16.7) & $46 / 173(26.9)$ & $<0.01^{\mathrm{d}}$ \\
\hline GOLD I, II, III, IV & $5,49,36,34$ & $1,8,7,4$ & $3,10,8,8$ & $1,17,5,6$ & $0,14,16,16$ & \\
\hline Asthma & $356 / 697(51.1)$ & $96 / 175(54.9)$ & $96 / 175(54.9)$ & $87 / 174(50.8)$ & $77 / 173(44.5)$ & $0.03^{\mathrm{d}}$ \\
\hline Other $^{\mathrm{h}}$ & $68 / 697(9.8)$ & $9 / 175(5.1)$ & $16 / 175(9.1)$ & 19/174 (10.9) & 24/173 (13.9) & $<0.01^{\mathrm{d}}$ \\
\hline Fibrosing alveolitis & 25/697 (3.6) & 3 & 6 & 4 & 12 & \\
\hline Sarcoidosis & $14 / 697(2.0)$ & 3 & 5 & 2 & 4 & \\
\hline Silicosis & $12 / 697(1.7)$ & 2 & 0 & 6 & 4 & \\
\hline Neither heart disease nor lung disease & $108 / 697(15.5)$ & $41 / 175(23.4)$ & $25 / 175(14.3)$ & $27 / 174(15.5)$ & $15 / 173(8.7)$ & $<0.01^{\mathrm{d}}$ \\
\hline \multicolumn{7}{|l|}{ NT-proBNP, pg/ml } \\
\hline All patients ${ }^{\mathrm{b}}$ & $72[33-182]$ & $58[22-118]$ & $64[32-164]$ & $67[29-131]$ & $137[59-551]$ & $<0.01^{\mathrm{e}}$ \\
\hline Without heart disease $(n=521)^{b}$ & $55[27-105]$ & $40[17-89]$ & $52[27-94]$ & $47[27-96]$ & $82[41-158]$ & $<0.01^{\mathrm{e}}$ \\
\hline With heart disease $(n=176)^{b}$ & $291[118-1,464]$ & $211[76-796]$ & $255[76-496]$ & $190[79-1,464]$ & $648[224-2,197]$ & $<0.01^{\mathrm{e}}$ \\
\hline
\end{tabular}

Figures in parentheses are percentages. ASD = Atrial septal defect; GOLD = Global Initiative for Chronic Obstructive Lung Disease.

${ }^{a}$ Mean values \pm 1 standard deviation. ${ }^{b}$ Median values, with interquartile ranges in brackets. ${ }^{c}$ Analysis of variance. ${ }^{\mathrm{d}}$ Cochran-Armitage test for trend. ${ }^{\mathrm{e}}$ Analysis of variance of $\ln$-transformed values of NT-proBNP.
${ }^{\mathrm{f}}$ Analysis of variance of $\ln$-transformed values of eGFR. ${ }^{\mathrm{g}}$ One patient had both atrial fibrillation and left bundle branch block. ${ }^{\mathrm{h}}$ The group also included patients with allergic alveolitis, chronic fibrotic tuberculosis, cryptogenic organizing pneumonia, cystic fibrosis and lymphomatoid granulomatosis.

\section{Results}

The baseline characteristics of the study participants and the distribution of cardiac and pulmonary disorders according to the corresponding quartiles of CRP levels are presented in table 1. Age and BMI increased across CRP quartiles. The prevalence of arterial hypertension also increased along the CRP quartile gradient, but this trend was no longer significant after adjusting for age and BMI. The median eGFR values decreased along the CRP gradient, but adjustment for age, sex, BMI and the presence of heart disease attenuated this trend, leaving little association ( $\mathrm{p}=0.14)$ between eGFR and CRP. An increase in the prevalence of COPD, other lung diseases and hypercapnic respiratory failure was observed with increasing quartiles of CRP, whereas the prevalence of asthma declined. The trends for COPD ( $p=0.05)$, other lung diseases $(\mathrm{p}=0.06)$ and asthma $(\mathrm{p}=0.31)$ were no longer significant after adjustment for age, sex, interaction of age and sex, BMI, eGFR and the presence of heart disease, whereas the trends for at least moderately severe airway obstruction $(\mathrm{p}<0.01)$ and hypercapnic respiratory failure $(\mathrm{p}=0.03)$ persisted. 


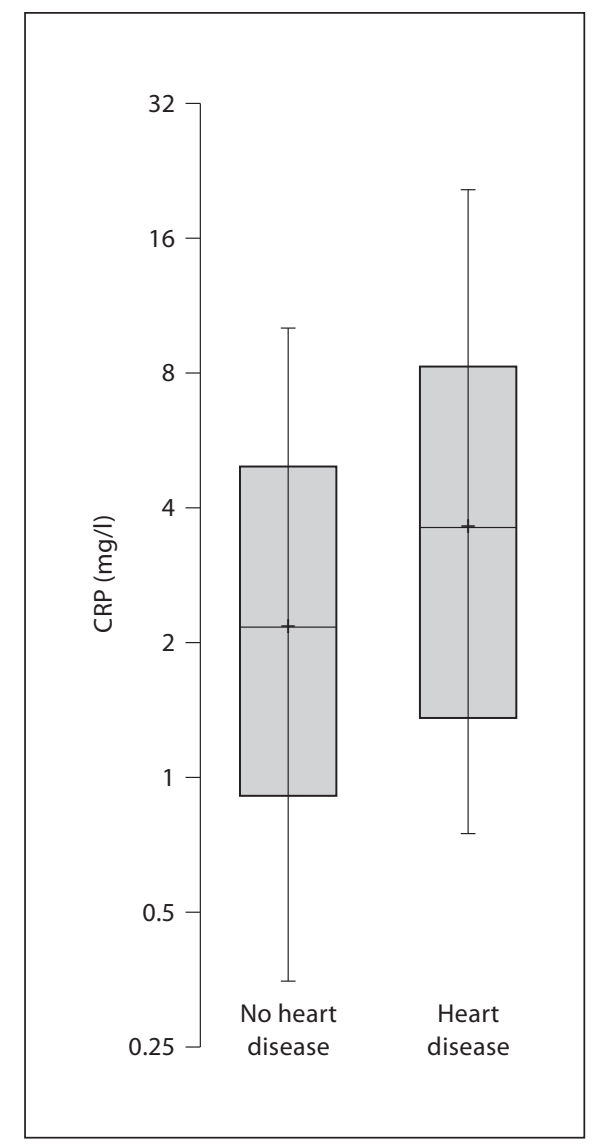

Fig. 1. Effect of heart disease on CRP. Data are presented as box and whisker plots. The line within the box denotes the median. The box spans the interquartile range. The whiskers extend from the 10 th to the 90th percentiles. Patients with heart disease $(\mathrm{n}=$ 176) had higher CRP values than patients without $(\mathrm{n}=521)$ heart disease (median values 3.69 vs. $2.18 \mathrm{mg} / \mathrm{l} ; \mathrm{p}<0.01$ ). The difference remained significant $(\mathrm{p}=0.02)$ after adjusting for age $(\mathrm{p}<0.01)$, BMI $(p<0.01)$, sex $(p=0.12)$, eGFR $(p=0.94)$ and the presence of lung disease $(\mathrm{p}<0.01)$.

Patients with heart disease displayed higher CRP values than those patients without heart disease, as shown in figure 1 (3.69 vs. $2.18 \mathrm{mg} / \mathrm{l} ; \mathrm{p}<0.01$ ). This difference remained significant $(\mathrm{p}=0.02)$ after adjustment for covariates. Figure 2 shows that COPD patients possessed higher CRP levels $(3.45 \mathrm{mg} / \mathrm{l})$ than those patients either with asthma or without lung disease $(2.19$ and $1.80 \mathrm{mg} / \mathrm{l}$, respectively; $\mathrm{p}<0.01)$. This difference also remained significant $(\mathrm{p}<0.01)$ after adjustment. The effect of the clinical classification into asthma or COPD on CRP was no longer significant $(\mathrm{p}=0.12)$ after adjustment for the severity of airway obstruction. Moderately severe and severe to very severe airway obstructions were associated

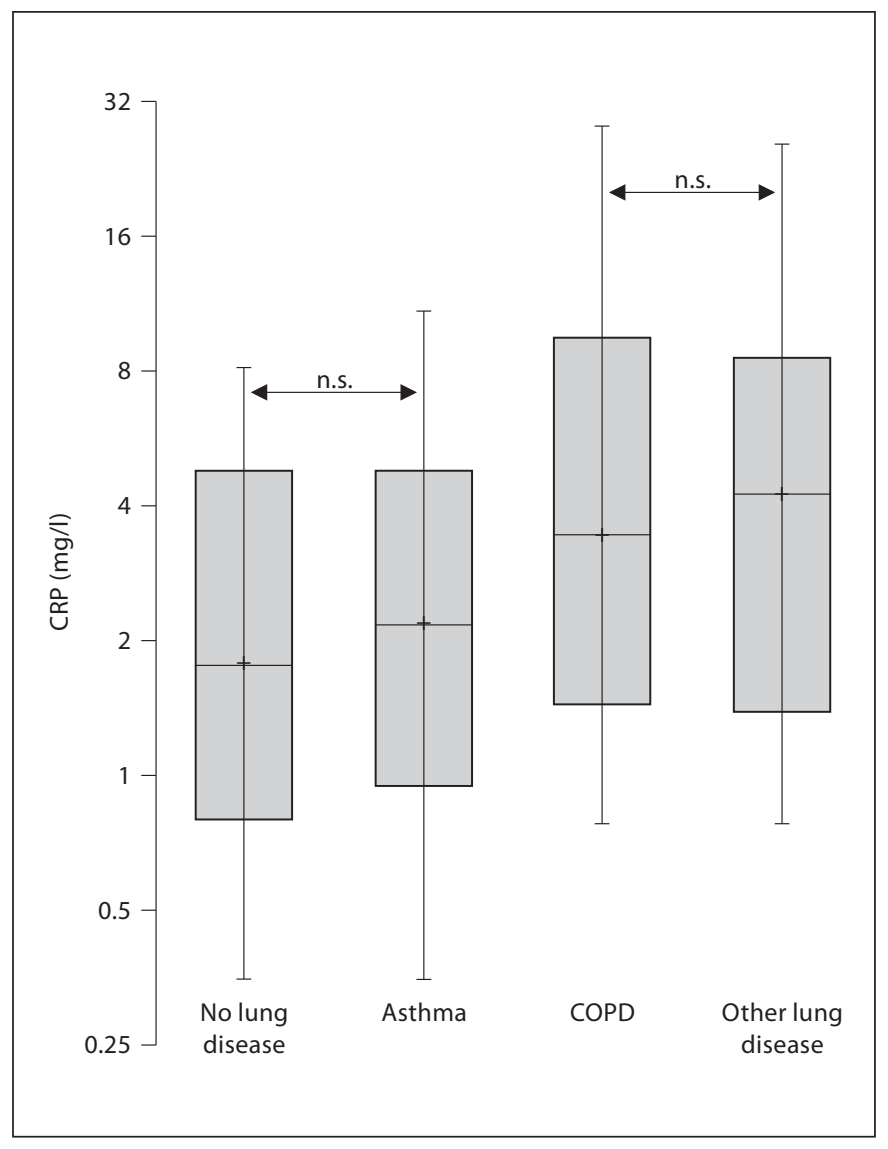

Fig. 2. Effect of lung disease on CRP. Data are presented as box and whisker plots. The line within the box denotes the median. The box spans the interquartile range. The whiskers extend from the 10 th to the 90 th percentiles. Patients with COPD $(n=124)$ had higher CRP values (median value $3.45 \mathrm{mg} / \mathrm{l}$ ) than patients either without lung disease $(\mathrm{n}=149$, median value $1.80 \mathrm{mg} / \mathrm{l})$ or with asthma ( $\mathrm{n}=356$, median value $2.19 \mathrm{mg} / \mathrm{l}$ ). The difference remained significant $(p<0.01)$ after adjustment for age $(p=0.05)$, BMI $(p<0.01)$, sex $(p=0.01)$, eGFR $(p=1.00)$ and the presence of heart disease $(p=0.02)$. The group summarized as 'other lung disease' predominantly consisted of patients with interstitial lung disease or pneumoconiosis. The median CRP value was 4.34 $\mathrm{mg} / \mathrm{l}$ in this group. The differences between patients with no lung disease and asthma and between patients with COPD and other lung disease were not significant (n.s.).

with increased CRP values as compared with no obstruction $(\mathrm{p}<0.01)$, whereas mild to moderate airway obstruction had no effect on CRP values $(\mathrm{p}=0.62)$. The median CRP value in patients with at least moderately severe airway obstruction was $3.50 \mathrm{mg} / \mathrm{l}$. Patients with at least moderately severe airway obstruction had a higher probability of CRP quartile 4 membership than those patients who had no obstruction (adjusted odds ratio 2.9; 95\% 
Fig. 3. Relationship between CRP quartile membership and the logarithmically transformed values for NT-proBNP adjusted for important covariates (see Data Analysis) in patients with and without heart disease. The y-axes have different starting points and span different ranges. The bars represent the 95\% confidence intervals. In both groups, the adjusted values for $\ln$ (NT-proBNP) were not different among CRP quartiles $1-3$ and were higher $(\mathrm{p}<0.01)$ in quartile $4(\mathrm{CRP}>5.80 \mathrm{mg} / \mathrm{l})$ than in quartiles $1-3$ (CRP $\leq 5.80 \mathrm{mg} / \mathrm{l})$. (Quartile 1: median $0.35 \mathrm{mg} / \mathrm{l}$; quartile 2: median $1.50 \mathrm{mg} / \mathrm{l}$; quartile 3: median 3.62 $\mathrm{mg} / \mathrm{l}$; quartile 4: median $10.90 \mathrm{mg} / \mathrm{l}$.)

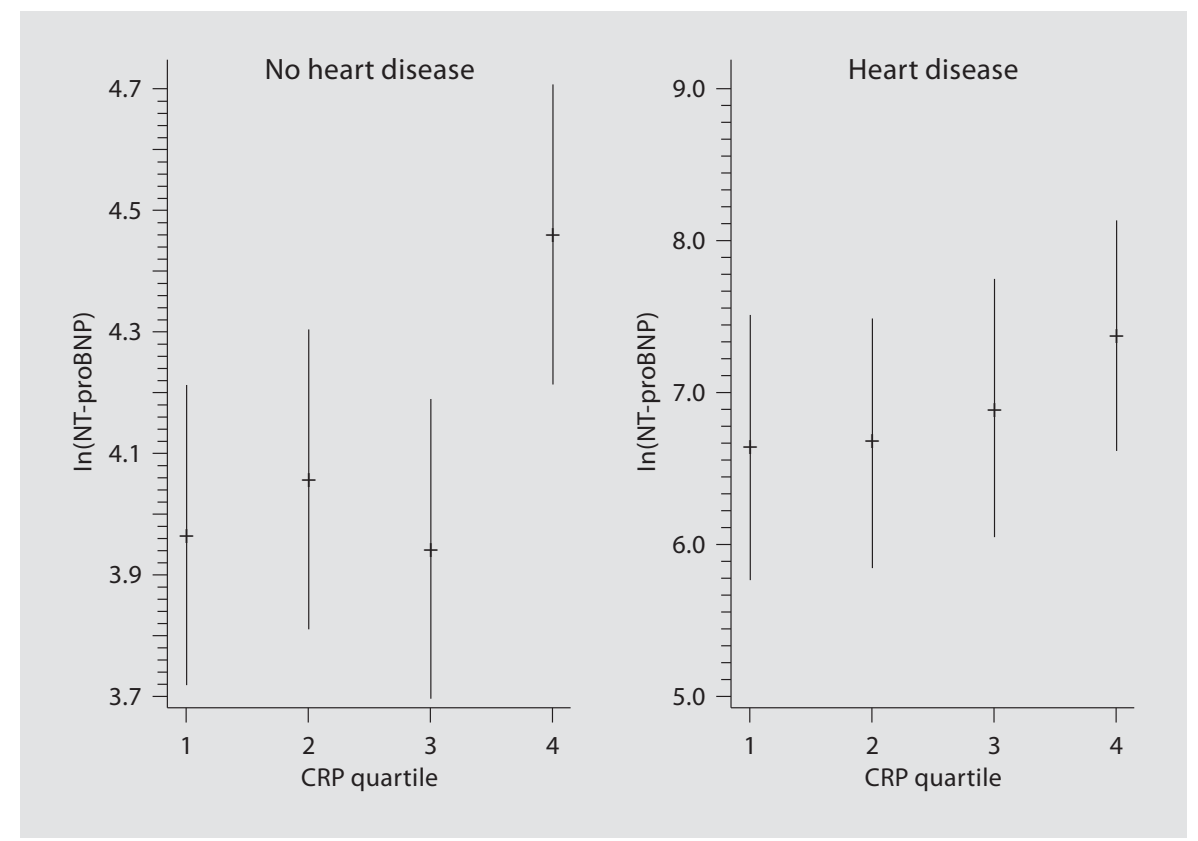

confidence interval 1.8-4.6; $\mathrm{p}<0.01$ ). Likewise, an increase in CRP was observed in the group categorized as 'other lung disease' (fig. 2) which primarily consisted of patients with restrictive ventilatory defects. These patients also had a higher probability of CRP quartile 4 membership than those having neither airway obstruction nor other lung diseases (adjusted odds ratio 2.9; 95\% confidence interval 1.5-5.7; $\mathrm{p}<0.01$ ).

In the 521 patients without heart disease, the values for NT-proBNP were lower in CRP quartiles 1-3 than in quartile 4 (median 47.4 vs. $82.1 \mathrm{pg} / \mathrm{ml} ; \mathrm{p}<0.01$ ) after adjusting for age $(\mathrm{p}<0.01)$, sex $(\mathrm{p}<0.01)$, interaction of age and sex $(\mathrm{p}=0.02)$, BMI $(\mathrm{p}<0.01)$, minor echocardiographic findings $(\mathrm{p}=0.07)$, eGFR $(\mathrm{p}=0.47)$ and arterial hypertension $(\mathrm{p}=0.07)$. The adjusted log-transformed values for NT-proBNP are shown in figure 3 . The presence of asthma, COPD or other lung diseases and the degree of airway obstruction had no effect on the relationship between CRP quartile and NT-proBNP values. The values for NT-proBNP were not different among CRP quartiles $1-3$. Similar results were observed in the 176 patients with heart disease. The NT-proBNP values were lower in CRP quartiles $1-3$ than in quartile 4 (median 212.0 vs. $647.7 \mathrm{pg} / \mathrm{ml} ; \mathrm{p}<0.01)$ after adjustment for age $(\mathrm{p}=0.08)$, sex $(p=0.74)$, interaction of age and sex $(p=0.72)$, BMI $(\mathrm{p}=0.31)$, minor echocardiographic findings $(\mathrm{p}<0.01)$, eGFR $(\mathrm{p}<0.01)$, arterial hypertension $(\mathrm{p}=0.98)$ and the cardiac characteristic groups. Again, no differences were detected between NT-proBNP values among CRP quartiles $1-3$, and the presence of lung disease and the degree of airway obstruction did not interact with the relationship between CRP quartile membership and NT-proBNP. A ranking order of various covariates of NT-proBNP as derived from their standardized regression coefficients is presented in table 2 .

\section{Discussion}

The results of this study show that CRP levels of $>5.80$ $\mathrm{mg} / \mathrm{l}$ are associated with increased NT-proBNP values in patients with and without heart disease. The cutoff value between CRP quartiles 1-3 and quartile 4 is close to the upper limit of normal that is used in clinical practice. The association between impaired lung function and systemic inflammation is clearly relevant, as $41.1 \%$ of the patients with at least moderately severe airway obstruction, $35.3 \%$ of those categorized as 'other lung disease' and $65.0 \%$ of the patients with hypercapnic respiratory failure were in the 4th CRP quartile. Our findings also show that the presence of lung disease and the severity of airway obstruction do not interact with the response of NTproBNP to CRP.

To our knowledge, the effect of systemic inflammation on NT-proBNP has not been previously reported. Resting NT-proBNP levels correlate inversely with peak 
Table 2. Ranking order of various determinants of NT-proBNP according to their standardized regression coefficients

\begin{tabular}{|c|c|c|c|c|}
\hline Ranking order & No heart disease & $\mathrm{p}$ value & Heart disease & $\mathrm{p}$ value \\
\hline 1 & Age & $<0.01$ & Impaired left ventricular function & $<0.01$ \\
\hline 2 & CRP quartile membership ${ }^{1}$ & $<0.01$ & Atrial fibrillation/left bundle branch block & $<0.01$ \\
\hline 3 & Sex 1 & $<0.01$ & Pulmonary hypertension & $<0.01$ \\
\hline 4 & BMI & $<0.01$ & eGFR & $<0.01$ \\
\hline 5 & Arterial hypertension & 0.07 & Minor echocardiographic finding ${ }^{2}$ & $<0.01$ \\
\hline 6 & Minor echocardiographic finding ${ }^{2}$ & 0.07 & CRP quartile membership ${ }^{1}$ & $<0.01$ \\
\hline 7 & eGFR & 0.47 & Valvular or congenital heart disease & 0.03 \\
\hline 8 & & & Age & 0.08 \\
\hline 9 & & & BMI & 0.31 \\
\hline 10 & & & Exercise-induced myocardial ischemia & 0.55 \\
\hline 11 & & & Sex & 0.74 \\
\hline 12 & & & Left ventricular hypertrophy & 0.89 \\
\hline 13 & & & Arterial hypertension & 0.98 \\
\hline
\end{tabular}

${ }^{1}$ CRP quartiles $1-3$ versus quartile 4.

${ }^{2}$ Mild aortic regurgitation, mild mitral regurgitation or systolic pressure gradient across the tricuspid valve of $30-34 \mathrm{~mm} \mathrm{Hg}$.

oxygen uptake and peak cardiac power output during symptom-limited exercise, such that NT-proBNP has gained acceptance as an indicator of the exercise cardiac reserve [10]. Oelberg et al. [25] advanced the argument that a blunted peak cardiac output might limit the exercise tolerance of patients with severe COPD. Our findings support this concept and may help to further clarify the link between advanced lung disease and impaired exercise cardiac reserve. We hypothesize that the inflammation-mediated cardiac stress causes a reduction of the exercise cardiac reserve, which contributes to the functional impairment of patients with advanced pulmonary disease. This excess burden on the heart is not trivial. To illustrate its magnitude, it is useful to compare the impact of CRP on NT-proBNP values in regard to the effects of age and arterial hypertension. In patients without heart disease, moving from CRP quartiles 1-3 to quartile 4 has the same effect on the log-transformed NT-proBNP values as a 15-year increase in age and exhibits a 2.4-fold greater effect than the presence of arterial hypertension. Table 2 shows that the effect of CRP quartile 4 membership on NT-proBNP is second only to the effect of age. In patients with heart disease, moving from CRP quartiles 1-3 to quartile 4 has the same effect on the adjusted NTproBNP values as a 31-year increase in age and a greater effect than exercise-induced myocardial ischemia and left ventricular hypertrophy.

A consensus panel on the role of CRP measurement in the assessment of cardiovascular risk classified CRP values into low- $(<1 \mathrm{mg} / \mathrm{l})$, intermediate- $(1-3 \mathrm{mg} / \mathrm{l})$ and high-risk ( $>3 \mathrm{mg} / \mathrm{l})$ categories [26]. Ridker et al. [27] used a CRP concentration of $\geq 2 \mathrm{mg} / \mathrm{l}$ as a criterion to identify higher-risk patients in a primary prevention trial. Our results do not suggest that moving from the low to the intermediate CRP risk category has a significant effect on cardiac stress and that a threshold value exists at a CRP level of $2 \mathrm{mg} / \mathrm{l}$ because there was no change in NTproBNP values from the 2 nd to the 3 rd CRP quartile in either group. Promotion of atherothrombosis by lowgrade inflammation probably plays a key role in the association between CRP and cardiac risk at CRP levels well below $5 \mathrm{mg} / 1$ [28]. Our findings provide another clue for why patients with advanced lung disease are at increased cardiac risk. In patients with heart failure, both $\mathrm{CRP}$ and BNP are powerful predictors of risk. However, the relation between CRP and risk does not depend on BNP [1]. In our patients without heart disease, the median NT-proBNP values increased from CRP quartiles 1-3 to quartile 4 within a range below contemporary threshold values used for ruling out heart failure. Of note is in this context that NT-proBNP levels currently regarded to be in the upper normal range may be associated with an excess risk of cardiovascular events [14]. Taken together, these data support the notion that ongoing cardiac stress in a pro-inflammatory environment is another link between advanced lung disease and increased cardiovascular risk even in patients without evidence of heart disease.

Table 1 shows that the prevalence of heart disease increased along the CRP quartile gradient. Accordingly, 
the median value for NT-proBNP increased almost 3 -fold from CRP quartiles 1-3 to quartile 4 in the group of patients with heart disease. Compared with CRP quartiles $1-3$, patients in CRP quartile 4 exhibited a higher prevalence of impaired left ventricular systolic function $(p<0.02)$, atrial fibrillation or left bundle branch block $(\mathrm{p}<0.01)$ and pulmonary hypertension $(\mathrm{p}<0.01)$. These disorders were the major determinants of NT-proBNP values, as shown in table 2 . Therefore, failure to adjust the NT-proBNP values for the type of heart disease would result in an overestimation of the direct effect of CRP on NT-proBNP values. We carefully controlled for the effect of the underlying heart disease on NT-proBNP by placing the cardiological findings into 6 characteristic groups and adjusting the NT-proBNP values for the type of heart disease. However, we cannot rule out the possibility that patients in CRP quartile 4 had more cardiac disease which was not diagnosed by the noninvasive methods used in this study. This limitation particularly applies to the diagnosis of myocardial ischemia, because ergometry was used to detect this condition. It can be assumed that some patients with myocardial ischemia had to stop the exercise test due to lung-related dyspnea, which further reduces test sensitivity. The following limitations also warrant mentioning. First, data to analyze diastolic function were not available in our patients [15]. Diastolic dysfunction is frequently associated with raised NT-proBNP levels. Second, we could not address the question regarding what types of heart disease were associated with elevated CRP values, because the numbers of patients in the 6 cardiac characteristic groups were too low to allow analysis of the effects of different types of heart disease on CRP separately. The same limitation applies to the patients classified as 'other lung disease'. Third, the smoking status of the participants was not objectively validated. Since the self-reported smoking status is unreliable, we were unable to assess the interaction between active cigarette smoking and CRP on NT-proBNP levels [29, 30]. Fourth, patients with ongoing exacerbations and those with other chronic inflammatory disorders were not excluded. By contrast, several previous studies on the relation between CRP and COPD carefully excluded patients with unstable disease or concomitant inflammatory disorders $[6,31$, 32]. This difference placed our study group at a higher prevalence of both systemic inflammation and cardiac stress. Furthermore, we did not adjust for current medications which may elicit anti-inflammatory or adverse cardiovascular effects [33-35]. Paradoxically, these limitations do not weaken the strength of our data, because our inclusion criteria and the lack of adjustment for potentially cardiotoxic medications tend to dilute the impact of an impaired lung function on CRP and the effect of systemic inflammation on NT-proBNP, respectively. Fifth, our study involved only patients with dyspnea. Hence, the results may not be generalizable to broader populations. Finally, NT-proBNP is not a direct measure of cardiac stress but is only a surrogate marker.

In summary, this study suggests that, in addition to the well-known effects of age, sex, BMI and renal function, CRP also affects NT-proBNP levels in patients with and without heart disease. Pulmonary status has no direct effect on the response of NT-proBNP to systemic inflammation. However, advanced obstructive pulmonary disease, interstitial lung disease or pneumoconiosis and hypercapnic respiratory failure are frequently associated with systemic inflammation. This condition places an excess burden on the heart, which may contribute to the functional impairment and the poor cardiovascular outcomes observed in these patients.

\section{References}

1 Anand IS, Latini R, Florea VG, Kuskowski MA, Rector T, Masson S, Signorini S, Mocarelli P, Hester A, Glazer R, Cohn JC; for the Val-HeFT Investigators: C-reactive protein in heart failure. Prognostic value and the effect of Valsartan. Circulation 2005;112: 1428-1434.

-2 Racki S, Zaputović L, Mavrić Z, Vujicić B, Dvornik S: C-reactive protein is a strong predictor of mortality in hemodialysis patients. Ren Fail 2006;28:427-433.
-3 Sin DD, Man SFP: Why are patients with chronic obstructive pulmonary disease at increased risk of cardiovascular diseases? The potential role of systemic inflammation in chronic obstructive pulmonary disease. Circulation 2003;107:1514-1519.

4 Mannino DM, Ford ES, Redd SC: Obstructive and restrictive lung disease and markers of inflammation: data from the Third $\mathrm{Na}$ tional Health and Nutrition Examination. Am J Med 2003;114:758-762.
5 Sin DD, Man SFP: Chronic obstructive pulmonary disease: a novel risk factor for cardiovascular disease. Can J Physiol Pharmacol 2005;83:8-13.

-6 Broekhuizen R, Wouters EFM, Creutzberg EC, Schols AMWJ: Raised CRP levels mark metabolic and functional impairment in advanced COPD. Thorax 2006;61:17-22.

7 Aliverti A, Macklem PT: How and why exercise is impaired in COPD. Respiration 2001; 68:229-239. 
-8 Maisel A, Mueller C, Adams K Jr, Anker SD, Aspromonte N, Cleland JGF, Cohen-Solal A, Dahlstrom U, DeMaria A, Di Somma S, Filippatos GS, Fonarow GC, Jourdain P, Komajda M, Liu PP, McDonagh T, McDonald K, Mebazaa A, Nieminen MS, Peacock WF, Tubaro M, Valle R, Vanderhyden M, Yancy CW, Zannad F, Braunwald E: State of the art: using natriuretic peptide levels in clinical practice. Eur J Heart Fail 2008;10: 824-839.

-9 Rutten FH, Hoes AW: B-type natriuretic peptide assays for detecting heart failure in the elderly: same value as those in the younger? Int J Cardiol 2008;125:161-165.

-10 Williams SG, Ng LL, O’Brian RJ, Taylor S, Wright DJ, Tan LB: Is plasma N-BNP a good indicator of the functional reserve of failing hearts? The FRESH-BNP study. Eur J Heart Fail 2004;6:891-900.

-11 Hole DJ, Watt GCM, Davey-Smith G, Hart CL, Gillis CR, Hawthorne VM: Impaired lung function and mortality risk in men and women: findings from the Renfrew and Paisley prospective population study. BMJ 1996; 313:711-715.

-12 Man SFP, Connett JE, Anthonisen NR, Wise RA, Tashkin DP, Sin DD: C-reactive protein and mortality in mild to moderate chronic obstructive pulmonary disease. Thorax 2006;61:849-853.

13 Dahl M, Vestbo J, Lange P, Bojesen SE, Tybjaerg-Hansen A, Nordestgaard BG: C-reactive protein as a predictor of prognosis in chronic obstructive pulmonary disease. Am J Respir Crit Care Med 2007;175:250-255.

-14 Wang TJ, Larson MG, Levy D, Benjamin EJ, Leip EP, Omland T, Wolf PA, Vasan RS: Plasma natriuretic peptide levels and the risk of cardiovascular events and death. N Engl J Med 2004;350:655-663.

15 Wieshammer S, Dreyhaupt J, Basler B, Marsovszky E: NT-proBNP for pulmonologists: not only a rule-out test for systolic heart failure but also a global marker of heart disease. Respiration 2009;77:370-380.

16 Global Initiative for Asthma (GINA), National Institutes of Health: NHLBI/WHO workshop report. Bethesda, National Heart, Lung and Blood Institute, National Institutes of Health, 2005. www.ginasthma.com.

-17 Celli BR, MacNee W, ATS/ERS Task Force: Standards for the diagnosis and treatment of patients with COPD: a summary of the ATS/ ERS position paper. Eur Respir J 2004;23: 932-946.
8 Pellegrino R, Viegi G, Brusasco V, Crapo RO, Burgos F, Casaburi R, Coates A, van der Grinten CPM, Gustafsson P, Hankinson J, Jensen R, Johnson DC, MacIntyre N, McKay R, Miller MR, Navajas D, Pedersen OF, Wanger J: Interpretative strategies for lung function tests. Eur Respir J 2005;26:948968.

19 Swanney MP, Ruppel G, Enright PL, Pedersen OF, Crapo RO, Miller MR, Jensen RL, Falaschetti E, Schouten JP, Hankinson JL, Stocks J, Quanjer PH: Using the lower limit of normal for the $\mathrm{FEV}_{1} / \mathrm{FVC}$ ratio reduces the misclassification of airway obstruction. Thorax 2008;63:1046-1051.

20 Levey AS, Coresh J, Greene T, Marsh J, Stevens LA, Kusek JW, van Lente F; for Chronic Kidney Disease Epidemiology Collaboration: Expressing the modification of diet in renal disease study equation for estimating glomerular filtration rate with standardized serum creatinine values. Clin Chem 2007;53: 766-772.

-21 Rumley A, Emberson JR, Wannamethee SG, Lennon L, Whincup PH, Lowe GDO: Effects of older age on fibrin D-dimer, C-reactive protein, and other hemostatic and inflammatory variables in men aged $60-79$ years. J Thromb Haemost 2006;4:982-987.

22 Khera A, Vega GL, Das SR, Ayers C, McGuire DK, Grundy SM, de Lemos JA: Sex differences in the relationship between C-reactive protein and body fat. J Clin Endocrinol Metab 2009;94:3251-3258.

23 Dietrich M, Jialal I: The effect of weight loss on a stable biomarker of inflammation, Creactive protein. Nutr Rev 2005;63:22-28.

24 Cachofeiro V, Goicochea M, de Vinuesa SG, Oubina P, Lahera V, Luno J: Oxidative stress and inflammation, a link between chronic kidney disease and cardiovascular disease. Kidney Int Suppl 2008:74(suppl 111):S4-S9.

25 OelbergDA, KacmarekRM, Pappagianopoulos P, Ginns LC, Systrom DM: Ventilatory and cardiovascular responses to inspired $\mathrm{He}-\mathrm{O}_{2}$ during exercise in chronic obstructive pulmonary disease. Am J Respir Crit Care Med 1998;158:1876-1882.
26 Pearson TA, Mensah GA, Alexander RW, Anderson JL, Cannon RO, Criqui M, Fadl YY, Fortmann SP, Hong Y, Myers GL, Rifai N, Smith SC, Taubert K, Tracy RP, Vinicor F: Markers of inflammation and cardiovascular disease. Application to clinical and public health practice. A statement for health care professionals from the Centers for Disease Control and Prevention and the American Heart Association. Circulation 2003;107: 499-511.

-27 Ridker PM, Danielson E, Fonseca FAH, Genest J, Gotto AM Jr, Kastelein JJP, Koenig W, Libby P, Lorenzatti AJ, MacFadyen JG, Nordestgaard BG, Shepherd J, Willerson JT, Glynn RJ; for the JUPITER Study Group: Rosuvastatin to prevent vascular events in men and women with elevated C-reactive protein. N Engl J Med 2008;359:2195-2207.

28 Topsakal R, Kalay N, Ozdogru I, Cetinkaya Y, Oymak S, Kaya MG, Dogan A, Inanc MT, Ergin A: Effects of chronic obstructive pulmonary disease on coronary atherosclerosis. Heart Vessels 2009;24:164-168.

29 Sato S, Nishimura K, Koyama H, Tsukino M, Oga T, Hajiro T, Mishima M: Optimal cutoff level of breath carbon monoxide for assessing smoking status in patients with asthma and COPD. Chest 2003;124:1749-1754.

>30 Gan WQ, Man SFP, Sin DD: The interactions between cigarette smoking and reduced lung function on systemic inflammation. Chest 2005; 127:558-564.

-31 de Torres JP, Cordoba-Lanus E, Lopez-Aguilar C, Muros de Fuentes M, Montejo de Garcini A, Aguirre-Jaime A, Celli BR, Casanova $\mathrm{C}$ : C-reactive protein levels and clinically important outcomes in stable COPD patients. Eur Respir J 2006;27:902-907.

32 Piehl-Aulin K, Jones I, Lindvall B, Magnuson A, Abdel-Halim SM: Increased serum inflammatory markers in the absence of clinical and skeletal muscle inflammation in patients with chronic obstructive pulmonary disease. Respiration 2009;78:191-196.

-33 Sin DD, Man SFP: Can inhaled steroids mend a broken heart in chronic obstructive pulmonary disease. Eur Respir J 2005;25: 589-590.

34 Cazzola M, Donner CF, Matera MG: Long acting $\beta_{2}$-agonists and theophylline in stable chronic obstructive pulmonary disease. Thorax 1999;54:730-736.

$\checkmark 35$ Cosio BG, Iglesias A, Rios A, Noguera A, Sala E, Ito K, Barnes PJ, Agusti A: Low-dose theophylline enhances the anti-inflammatory effects of steroids during exacerbations of COPD. Thorax 2009;64:424-429. 